\title{
The chemistry of organohalogenic molecules. Part 172. Kinetic studies of bromine transfer from $N$-bromosuccinimide to norbornene under protic conditions
}

\author{
Marko Zupan, Primož Škulj, and Stojan Stavber \\ Laboratory of Organic and Bioorganic Chemistry, Faculty of Chemistry and Chemical \\ Technology, University of Ljubljana and J. Stefan Institute, Aškerčeva 6, SI-1000 Ljubljana, \\ Slovenia \\ E-mail: marko.a.zupan@uni-lj.si
}

\section{Dedicated to Prof. Dr. Miha Tišler on the occasion of his $75^{\text {th }}$ birthday \\ (received 15 Feb 01; accepted 28 Jan 02; published on the web 05 Feb 02)}

\begin{abstract}
Kinetic studies of bromofunctionalisation of cycloalkenes with N-bromosuccinimide (NBS) in acetonitrile-water under various conditions were carried out. Reaction with bicyclo[2,2,1] heptene (norbornene) in acetonitrile-water solution gave three main products: 2-exo-hydroxy-7-synbromo norbornane, 2-exo- hydroxy-7-anti-bromo norbornane and bromonortricyclane in 5:1:1 ratio. The course of the reaction obeys a simple rate equation:

$$
\mathbf{v}=\mathbf{d}[\mathrm{NBS}] / \mathrm{dt}=\mathbf{k}_{2}[\mathrm{NBS}][\text { alkene] }
$$

with $\mathbf{k}_{2}=\mathbf{0 . 3 5} \mathbf{M}^{-1} \mathbf{s}^{-1}$ at $10^{\circ} \mathrm{C}$. In order to obtain further insight into the nature of the transition state during the bromine transfer from NBS, the effect of cycloalkene ring size was investigated and the following relative values were determined: 9.7 for the norbornene/cyclohexene pair, while a lower structural effect was found for the cyclopentene/cyclohexene pair, i.e. 1.2. For the bromination of norbornene the following activation parameters were determined: $\Delta \mathbf{H}^{\ddagger}=\mathbf{6 . 1} \mathbf{~ k c a l}$ $\mathbf{m o l}^{-1}, \Delta \mathbf{S}^{\ddagger}=-\mathbf{3 8} \mathrm{cal} \mathrm{mol}^{-1} \mathbf{K}^{-\mathbf{1}}$. The solvent polarity variation (Grunwald - Winstein Y) was used to obtain information about the nature of the rate determining step in bromine transfer from NBS to norbornene and $\mathbf{m}=\mathbf{0 . 8}$ was determined, indicating a large change in the polarity of the transition state as compared to the reactants. The observed kinetic data suggests that the rate determining transition state in bromofunctionalisation of cyclic alkenes has a three-centered cyclic structure, the nucleophile also playing an important role.
\end{abstract}

Keywords: Cycloalkenes, N-bromosuccinimide, bromofunctionalisation, kinetics, activation parameters, solvent polarity 


\section{Introduction}

It has already been demonstrated that bicyclo[2,2,1]heptene (norbornene) is one of the most versatile model olefins in studies of the role of reagent structure of electron acceptor type E-L reagents on the course of the addition reaction. ${ }^{1-6}$ From these studies, two types of information can be obtained: the structures of the products and their distribution inform us about the type of electron shift from the $\pi$ electron system to acceptor $E-L$ reagent;1- 6 the relative rates of functionalisation of norbornene versus cyclohexene inform us about the geometry of the rate determining transition state, ${ }^{7}$ being insensitive in the case of a three-centered intermediate

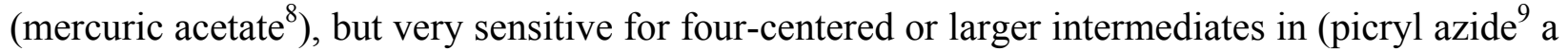
rate ratio up to $8 \cdot 10^{3}$ was observed).

Valuable information concerning the geometry and the polarity of the rate determining transition state can be obtained by solvent polarity studies of functionalisations of organic molecules. ${ }^{10}$ Larger effects are expected when a non-polar substrate and the reagents proceed during the rate determining step over a polar transition state forming charged intermediates as observed in the classical paper on solvolysis of tert-butyl chloride11 where a correlation coefficient of $\mathrm{m}=1$ was established. A similar high solvent polarity effect was also recently observed for addition of bromine to methylidenadamantane. ${ }^{12}$

$\mathrm{N}$-bromosuccinimide (NBS) appears to be one of the most extensively studied reagents of the non-polar E-L family with wide ranging reactivity: from ionic type of functionalisation with electron donating molecules, to electron transfer modes of activation. NBS is also a convenient source of bromine radicals under appropriate reaction conditions. ${ }^{4-6,13,14}$

Because of our continuing interest in mild reagents for the introduction of halogens into organic molecules and because only limited kinetic information is available on $\mathrm{N}$ bromosuccinimide reactions with electron donor molecules, we found it important to determine kinetic parameters for the bromofunctionalisation of cycloalkenes in acetonitrile-water solutions. The results should give us further insight about the nature of the rate determining transition states in the transfer of bromine from $\mathrm{N}-\mathrm{X}$ type of reagents which can also help us to improve our knowledge of the transfer of other halogens, notably fluorine from $\mathrm{N}-\mathrm{F}$ type of reagents.

In Scheme 1 we show three types of electron acceptor molecules usually called electrophilic reagents $\left(\mathrm{E}-\mathrm{L}, \mathrm{E}^{+} \mathrm{L}^{-}, \mathrm{E}^{\delta+}-\mathrm{L}^{\delta-}\right)$. Their reactivity strongly depends on the nature of the $\mathrm{E}$ and $\mathrm{L}$ part of the reagent on one hand and on the structure of the alkene molecule on the other. The structure of the products and their distributions observed in reactions of norbornene with various electron accepting reagents provides important information on the type of the electron shift from the alkene and the geometry of the intermediates which in some cases can prevent the usually observed rearrangement processes. Unrearranged 2-exo-3-exo disubstituted products are observed when cyclic intermediates are involved, as in case of nitrosyl chloride15 addition, while reaction with peracids gives epoxide. ${ }^{16}$ On the other hand 2,3-disubstituted products (exo or endo) can also be observed after radical attack, ${ }^{17}$ and 2-exo-3-endo products are also formed after ionic attack with a cyclic intermediate structure preventing rearrangements or hydride 


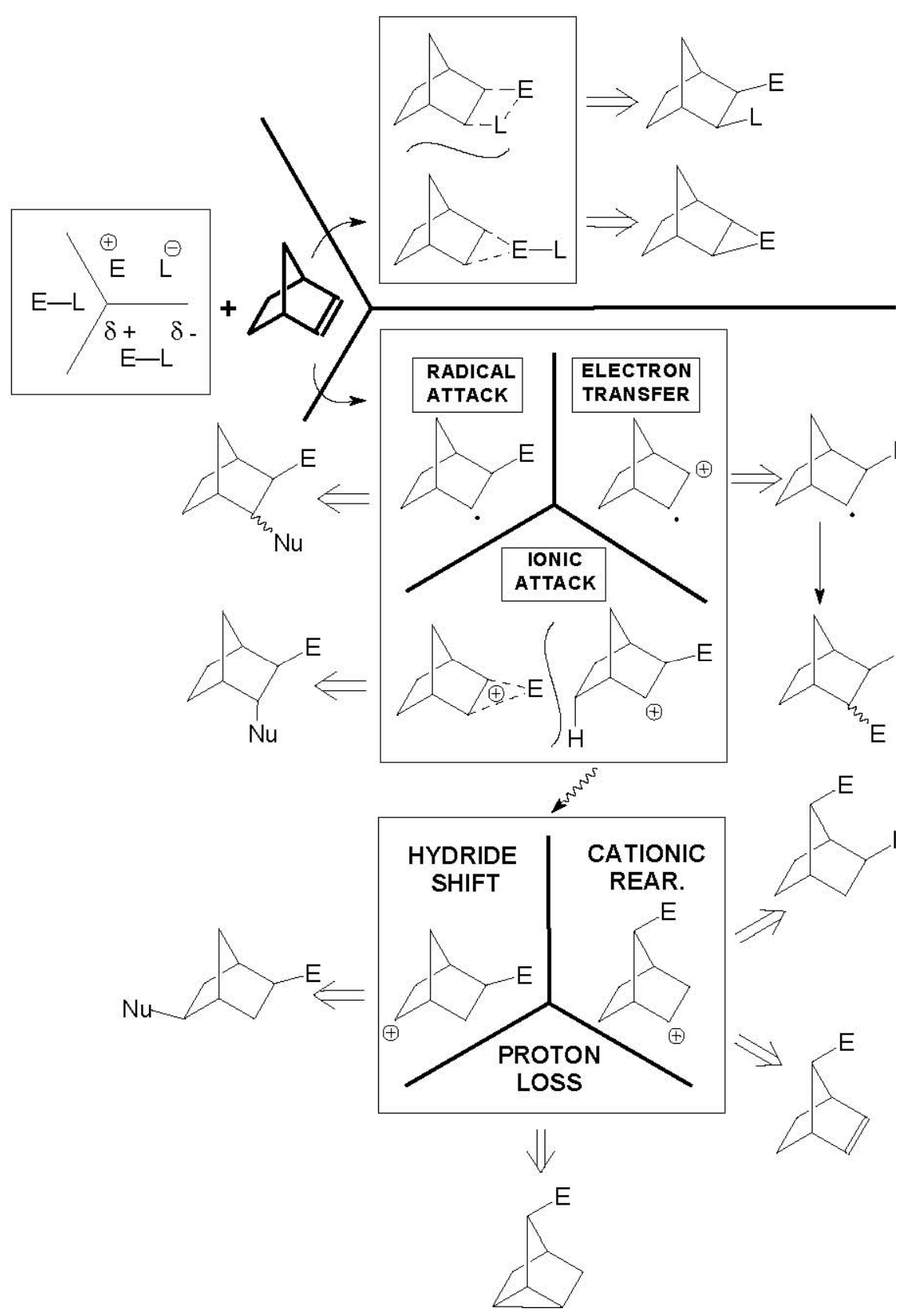

Scheme 1. Norbornene as a mechanistic tool for differentiation of reaction pathways in addition reactions with $\mathrm{E}-\mathrm{L}$ type of reagents $(\mathrm{Nu}$ : $\mathrm{L}$ or external nucleophile).

migrations e.g. addition of aryl sulpheny chloride. ${ }^{18}$

It has also been confirmed that ion radicals formed from norbornene do not rearrange and are further transformed with nucleophilic species to radical intermediates, and generally give 2-exo3-endo or 2-exo-3-exo disubstituted products. ${ }^{19}$ Reactions proceeding through partially bridged or open carbocationic intermediates will result in up to eight products formed after cationic rearrangement, hydride shift or proton loss. The mentioned processes can be repeated e.g. 
hydride migration taking place after primary Meerwein - Wagner rearrangement. Product distributions in this type of functionalisations are mainly influenced by the nature of the electrophilic species, solvent polarity and catalyst used. Thus the role of the electrophilic part of the reagent on the course of functionalisation can be nicely illustrated with halogens: low temperature reaction with fluorine gave only 7 -syn-fluoronorbornene, ${ }^{20}$ room temperature reaction with chlorine in the presence of oxygen gave mainly chloronortricyclane $(65,5 \%)$ and 2 exo-7-syn-dichloronorbornane $(25,1 \%),{ }^{21}$ while a similar pattern was also observed in low temperature bromine addition, proton loss being less abundant (45,5\% bromonortricyclane) with increasing Meerwein - Wagner rearranged product (30,7\% 2-exo-7-syn-dibromonorbornane). ${ }^{22}$ In the reaction with iodine monochloride predominant formation of a three-centered intermediate was reflected in the formation of 2-exo-iodo-3-endo-chloronorbornane (35\%) and rearranged 2exo-chloro-7-syn-iodonorbornane $(40 \%)$ as the main products. $^{23}$

\section{Results and Discussion}

Bromination of norbornene was extensively investigated either by bromine in various solvents ${ }^{22}$ or with NBS in a water-dimethylsulphoxide mixture, ${ }^{24}$ while rates of bromination were also determined. ${ }^{7,8}$ Halogen transfer from the $\mathrm{N}$ type of reagents is very sensitive to reaction conditions, especially in the case of fluorine transfer where acetonitrile as solvent affects the reactions to form Ritter type fluoroamides, whereas in the presence of a nucleophile vicinal fluoro-hydroxy or fluoro-alkoxy products are formed. ${ }^{25-28}$ In order to obtain kinetic and thermodynamic activation information comparable to that on fluorine transfer, ${ }^{29}$ we decided first to investigate the products formed in bromination of norbornene with NBS in acetonitrile in the presence of water. From the crude reaction mixture, three main products were isolated by preparative GC, and their structure confirmed by comparison of the spectroscopic data with the literature. $^{24}$ Three main products, 2-exo-hydroxy-7-syn-bromonorbornane, 2-exo-hydroxy-7-antibromonorbornane and bromonortricyclane, were formed in the ratio 5:1:1 (80 percent of crude reaction mixture). The rest of the crude reaction mixture was composed of at least four minor products. GC-MS indicated the presence of two Ritter type bromoacetamido products, as well as adducts with succinimide. 

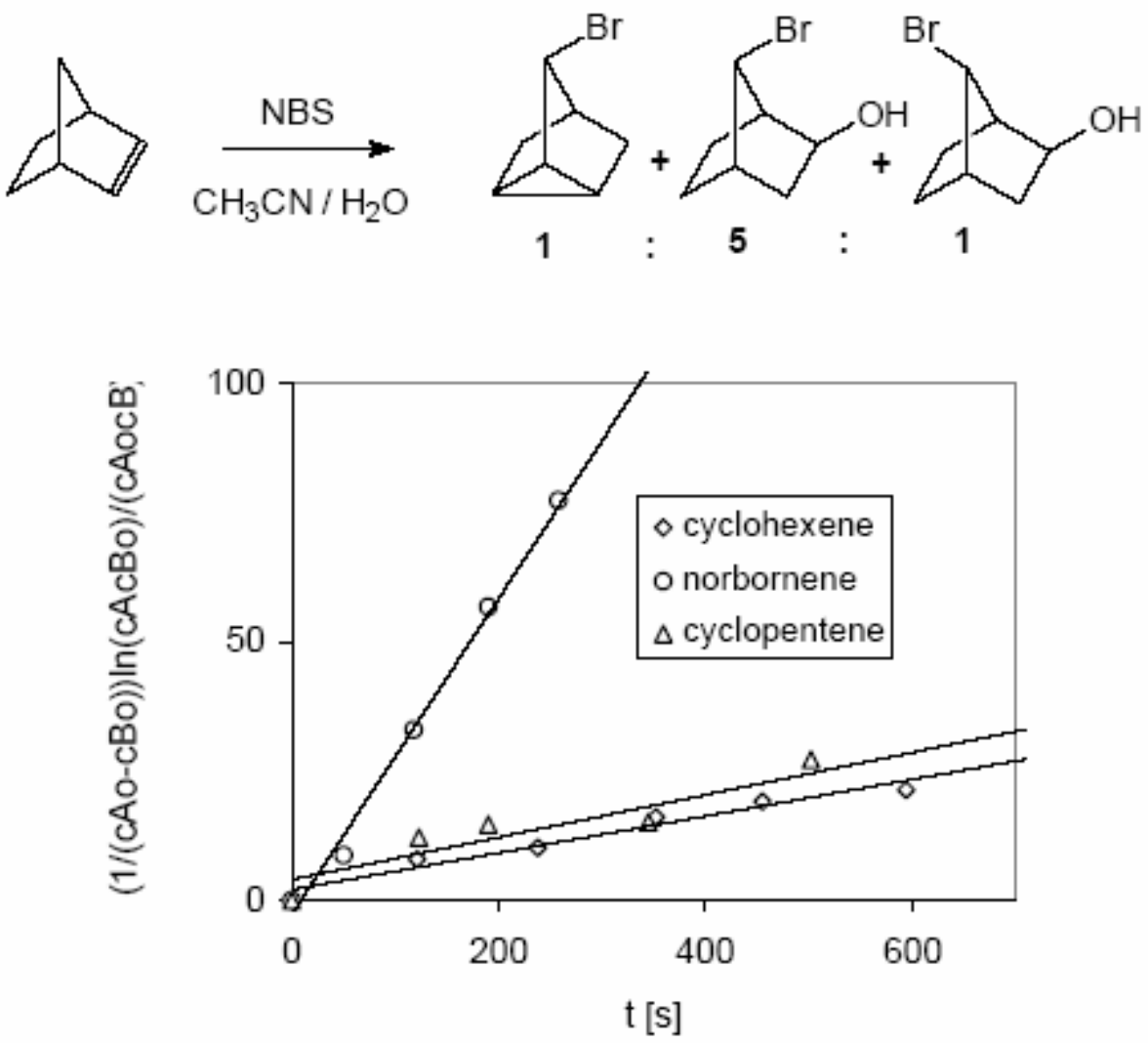

Scheme 2. Bromofunctionalisation of norbornene as compared to cyclohexene and cyclopentene.

The primary aim of this work was to determine the kinetic parameters of bromine transfer from NBS to cycloalkenes so therefore we studied the rate of bromohydroxylation at $10{ }^{\circ} \mathrm{C}$. The progress of reaction was monitored by iodometric titration, and clearly indicated that the course of reaction obeys a simple second order rate equation: $\mathrm{v}=\mathrm{d}[\mathrm{NBS}] / \mathrm{dt}=\mathrm{k}_{2}$ [NBS] [alkene].

Typical progress of the norbornene bromination reaction at $10{ }^{\circ} \mathrm{C}$ in acetonitrile-water mixture is presented in Scheme 2 and a value of $\mathrm{k}_{2}=0.35 \mathrm{M}^{-1} \mathrm{~s}^{-1}$ was determined.

Further, we investigated the activation parameters for bromine transfer to norbornene in acetonitrile-water solution, and the results are visualized in Figure 1 and in Table 1. The values $\Delta \mathrm{H}^{\ddagger}=6.1 \mathrm{kcal} \mathrm{mol}^{-1}, \Delta \mathrm{S}^{\ddagger}=-38 \mathrm{cal} \mathrm{mol}^{-1} \mathrm{~K}^{-1}$ found can be compared to already determined activation profiles for other functionalisations of norbornene: addition of picrylazide in chloroform ${ }^{9} \Delta \mathrm{H}^{\ddagger}=9.8 \mathrm{kcal} \mathrm{mol}^{-1}, \Delta \mathrm{S}^{\ddagger}=-33.4 \mathrm{cal} \mathrm{mol}^{-1} \mathrm{~K}^{-1}$ and phenylazide under similar conditions $^{9} \Delta \mathrm{H}^{\ddagger}=13.9 \mathrm{kcal} \mathrm{mol}^{-1}, \Delta \mathrm{S}^{\ddagger}=-33.1 \mathrm{cal} \mathrm{mol}^{-1} \mathrm{~K}^{-1}$. 


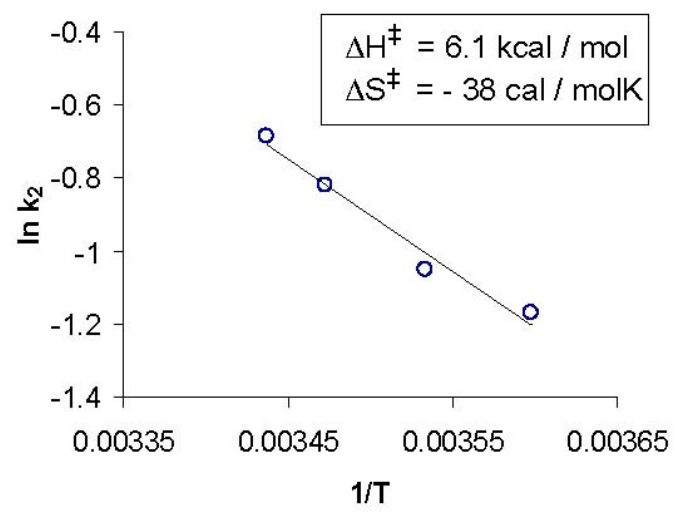

Figure 1. Effect of temperature on the reaction of norbornene with N-bromosuccinimide in acetonitrile - water solution.

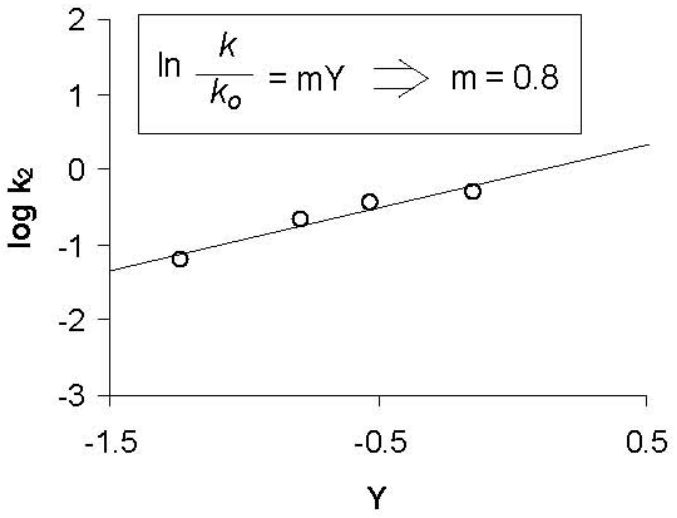

Figure 2. Effect of solvent polarity on the rate of reaction of norbornene with $\mathrm{N}$ bromosuccinimide in various acetonitrile water solutions.

Next we studied the effect of solvent polarity on the rate of bromofunctionalisation of norbornene. Due to the sensitivity of the bromofunctionalisation process to solvent, reactions are restricted to water-acetonitrile solutions. The solvent sensitivity observed in bromofunctionalisation with NBS is the same as that observed in bromination of 3phenylpropene $12(\mathrm{~m}=0.8$; Figure 2 , Table 1$)$, indicating that the change in polarity between the reactants and rate determining step in bromofunctionalisation with NBS is substantial. It is interesting to compare bromine transfer with fluorine transfer from 1-fluoro-4-hydroxy-1,4diazoniabicyclo[2,2,2] octane bis(tetrafluoroborate) to phenyl substituted alkenes, where a small negative value was found $(\mathrm{m}=-0.2) .^{30}$

Table 1. Effect of temperature and solvent polarity on second order rate constants for functionalisation of norbornene with N-bromosuccinimide

\begin{tabular}{ll||c||cc}
$\mathbf{T}\left[{ }^{\circ} \mathrm{C}\right]$ & $\mathbf{Y}$ & $\mathbf{k}_{\mathbf{2}}\left[\mathrm{M}^{-1} \mathrm{~S}^{-1}\right]$ & & \\
\hline \hline $\mathbf{5}$ & & $\mathbf{0 . 3 1} \pm 0.03$ & & \\
10 & -0.53 & $\mathbf{0 . 3 5} \pm 0.02$ & $\Delta \mathbf{H}^{\ddagger}=\mathbf{6 . 1} \pm 0,6$ & $\Delta \mathbf{S}^{\ddagger}=\mathbf{3 8} \pm 4,4$ \\
15 & & $\mathbf{0 . 4 4} \pm 0.01$ & {$\left[\mathrm{kcal} \mathrm{mol}^{-1}\right]$} & {$\left[\mathrm{cal} \mathrm{mol} \mathbf{K}^{-1} \mathrm{~K}^{-1}\right]$} \\
18 & & $\mathbf{0 . 5 0} \pm 0.02$ & & \\
\hline 10 & -1.23 & $\mathbf{0 . 0 6} \pm 0.004$ & & \\
& -0.79 & $\mathbf{0 . 2 1} \pm 0.02$ & $\mathbf{l n} \mathbf{k} / \mathbf{k}_{\mathbf{0}}=\mathbf{m Y}$ & $\mathbf{m}=\mathbf{0 . 8}$ \\
& -0.14 & $\mathbf{0 . 5 0} \pm 0.01$ & & \\
\hline
\end{tabular}

Finally, we studied the effect of ring size of the cycloalkene on the rate of bromofunctionalisation and similar second order rate behavior was established for cyclopentene and cyclohexene; constants determined at $10{ }^{\circ} \mathrm{C}$ were $\mathrm{k}_{2}=0.044 \mathrm{M}^{-1} \mathrm{~s}^{-1}$ for cyclopentene and 
$0.036 \mathrm{M}^{-1} \mathrm{~s}^{-1}$ for cyclohexene (Scheme 2). It is known that the relative rates of the norbornene / cyclohexene pair are much more dependent on the nature of the reagent, and therefore on the type of the intermediate (three-centered, four-centered, etc.) than in the case of the cyclopentene / cyclohexene pair. Table 2 summarizes various reagents and it is clear that bromofunctionalisation with NBS in acetonitrile-water solution lies in the middle of the table with values of 9.7 for the norbornene / cyclohexene pair and of 1.2 for the cyclopentene / cyclohexene pair. The three-centered structure of the intermediate is common to the functionalisation with mercuric acetate ${ }^{8}$ and peroxy acids 31 reflected in very low relative ratios, while larger ratios are observed for four or even five-centered cyclic intermediates where values of 660 and $8 \cdot 10^{3}$ were found for reactions with nitrosyl chloride ${ }^{8}$ and picryl azide ${ }^{9}$, respectively.

Scheme 3 presents possible structure of the rate determining transition state. The reaction scheme must take into account the carbocationic structure of the intermediate, due to Meerwein Wagner rearrangements and hydride shifts and a large solvent polarity factor $\mathrm{m}=0.8$, indicating large charge development during the transformation.

Table 2. Effect of reagent structure on the norbornene / cyclohexene and cyclopentene / cyclohexene reactivity ratios

\begin{tabular}{|c|c|c|}
\hline \multirow[b]{2}{*}{ Reagent } & \multicolumn{2}{|c|}{ Relative rate } \\
\hline & & \\
\hline $\mathrm{Hg}(\mathrm{OAc})_{2}{ }^{8}$ & 1 & 0.8 \\
\hline $\mathrm{RCOOH}^{31}$ & 1.3 & 1.5 \\
\hline $\mathrm{ISCN}^{8}$ & 7.1 & 2.1 \\
\hline NBS & 9.7 & 1.2 \\
\hline $\mathrm{Br}_{2}^{8}$ & 13 & 3.5 \\
\hline $\mathrm{ArSCl}^{8}$ & 33 & 3.3 \\
\hline $\mathrm{NOCl}^{8}$ & 660 & 88 \\
\hline $\mathrm{ArN}_{3}{ }^{9}$ & 8000 & 42 \\
\hline
\end{tabular}

As evident from Table 2 for the reaction occurring through the three-centered intermediate, lower relative rates (norbornene / cyclohexene) would be observed, while functionalisation via a four centered intermediate should be reflected in much higher relative rates (nitrosyl chloride $=$ 660 , picryl azide $=8 \cdot 10^{3}$ ). Bromofunctionalisation of cycloalkenes with NBS in protic polar solvents therefore probably occurs through a bridged three-centered transition state where the nucleophile plays an important role in the functionalisation, transferring to the bromonium ion 
giving, after proton loss, bromonortricyclane. The primarily formed bromonium ion undergoes further Meervein - Wagner rearrangement, while reaction with water gives 2-exo-hydroxy-7syn-bromo-norbornane. The rearranged bromonium ion can further undergo hydride shift and react with nucleophile giving 2-exo-hydroxy-7-anti-bromo-norbornane. A similar enhanced Meervein - Wagner rearrangement compared to proton loss was also observed in bromofluorination of norbornene with NBS / HF -pyridine. ${ }^{32,33}$
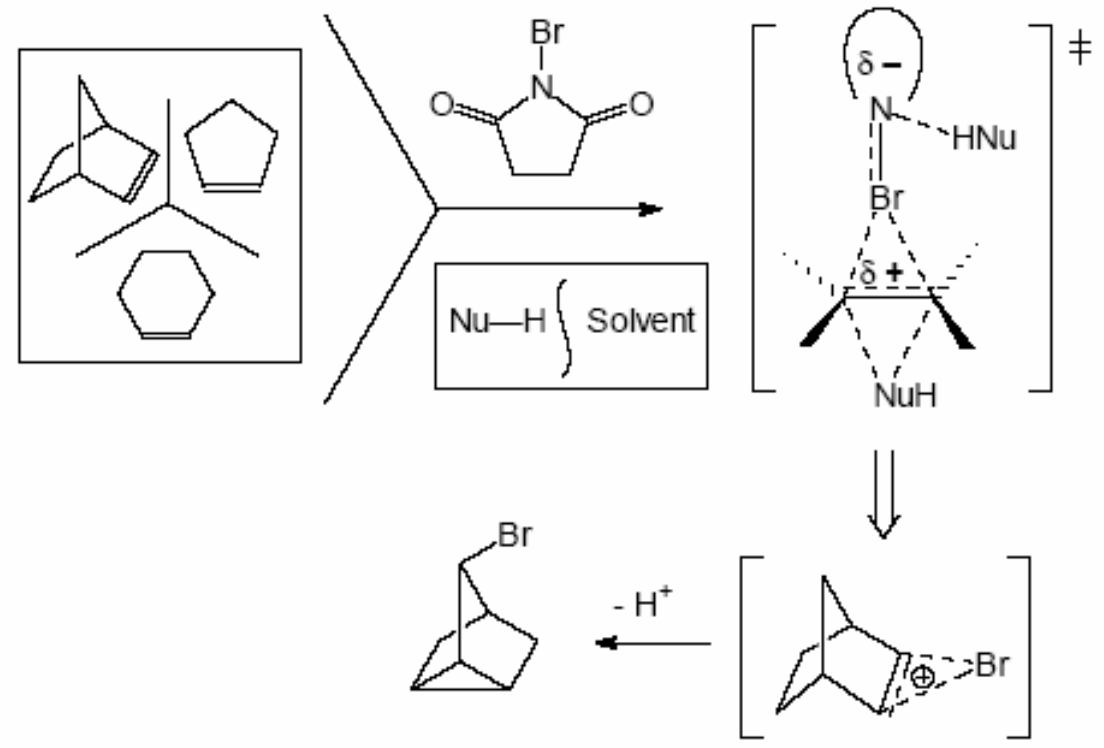

$\Downarrow$<smiles>BrC1CC2CCC(C1)C2Br</smiles><smiles>C[14CH3]</smiles>
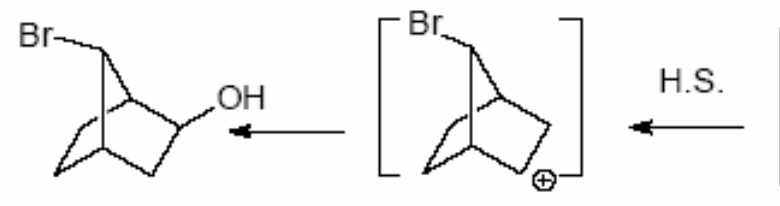<smiles>BrC1C2CC3CC1C(C2)C3Br</smiles>

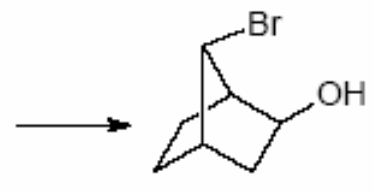

Scheme 3. Reaction pathways in the bromofunctionalisation of cyclic alkenes.

\section{Experimental Section}

General Procedures. N-bromosuccinimide (crystallized from acetonitrile), norbornene (sublimed), cyclopentene and cyclohexene (distilled) and the solvents (distilled) were obtained from commercial sources. KI and a standard solution of $\mathrm{Na}_{2} \mathrm{~S}_{2} \mathrm{O}_{3}$ were used as received. ${ }^{1} \mathrm{H}$ NMR spectra at $300 \mathrm{MHz}$ in $\mathrm{CDCl}_{3}$ were recorded on a Brukker 300, IR spectra on a PE 1310 spectrometer and mass spectra on an Autospec Q EI apparatus. Gas chromatography was carried out on a Varian 3350. 
Bromination of alkenes with NBS. Isolation and separation of products. 1,2 mmol of NBS was added to a solution of $1 \mathrm{mmol}$ of alkene in $5 \mathrm{~mL}$ of acetonitrile and $1 \mathrm{~mL}$ of water, and the reaction mixture stirred at $10{ }^{\circ} \mathrm{C}$ for 1 hour (norbornene), for 6 hours (cyclopentene and cyclohexene). The solvent was partially removed under reduced pressure and extracted with dichloromethane. The solution was washed with water and dried over sodium sulphate. The crude reaction mixture, after careful evaporation of solvent, was analysed by ${ }^{1} \mathrm{H}$ NMR spectroscopy and GC (HP-1 column). Norbornene: Three main products were isolated by preparative GC on a FFAP column and their structure determined on the basis of their spectroscopic data and by comparison to the literature ${ }^{24}$. 7-syn-bromo-2-exo-hydroxy norbornane (45 mg, 26\%) 7-anti-bromo-2-exo-hydroxy norbornane (8 mg, 5\%) bromonortricyclane $(25 \mathrm{mg}, 15 \%)$. The ratio of products was determined by G.C. and the mentioned products were formed in the ratio $5: 1: 1$. Mass spectra of all substances were recorded by GCMS (Autospec Q EI). Cycloalkenes: Structures of bromo-hydroxy cycloalkanes were confirmed on basis of their spectroscopic data and compared to the literature. ${ }^{34}$

\section{Determination of second order rate constants for bromination of alkenes with NBS.}

Various amount of alkene (norbornene, cyclopentene, cyclohexene), $(0.48,0.6,0,72 \mathrm{mmol}$ ) was dissolved in a thermostatted mixture of $30 \mathrm{~mL}$ acetonitrile and $10 \mathrm{~mL}$ water, then $20 \mathrm{~mL}$ of the thermostatted acetonitrile solution of NBS was added $(0.6 \mathrm{mmol})$ and the reaction mixture further stirred at $10{ }^{\circ} \mathrm{C}$. NBS consumption was monitored by iodometric titration: after various times. $10 \mathrm{~mL}$ aliquots of reaction mixture were mixed with $20 \mathrm{~mL}$ of cold $0,02 \mathrm{M} \mathrm{KI}$ and the liberated iodine was titrated with $0.05 \mathrm{M} \mathrm{Na}_{2} \mathrm{~S}_{2} \mathrm{O}_{3}$. Second order rate constants were calculated from the equation:

$1 /\left(C_{A o}-C_{B o}\right) \ln \left(C_{B o} C_{A}\right) /\left(C_{B} C_{A o}\right)=k_{2} t$

The following constants were determined for reactions in acetonitrile-water $5: 1$ solutions; $\mathrm{k} 2\left(\right.$ for norbornene) $=0.35 \pm 0.02 \mathrm{M}^{-1} \mathrm{~s}^{-1}, \mathrm{k}_{2}$ (for cyclopentene $)=0.044 \pm 0.004 \mathrm{M}^{-1} \mathrm{~s}^{-1}, \mathrm{k}_{2}($ for cyclohexene $)=0.036 \pm 0.001 \mathrm{M}^{-1} \mathrm{~s}^{-1}$. Measurements were repeated in at least 3 runs and average data is presented in Table 1.

Influence of solvent polarity on second order rate constants for bromination of norbornene with NBS. NBS $(0.6 \mathrm{mmol})$ dissolved in $20 \mathrm{~mL}$ thermostatted acetonitrile was added to $0,6 \mathrm{mmol}$ of norbornene dissolved in $40 \mathrm{~mL}$ thermostatted various acetonitrile-water mixtures so that total portions of water in acetonitrile were $10 \%, 13 \%, 17 \%$ and $20 \%$. Due to enhanced reactivity in mixtures with larger amounts of water, measurements were limited to solutions containing up to $20 \%$ water, while results for $30 \%$ were non-reproducible. Thermostatted mixtures were stirred at $10{ }^{\circ} \mathrm{C}$ and aliquots were iodometrically analysed. The second order rate constants are shown in Table 1 and were plotted according to the Winstein Gruenwald equation: $\log k_{2}=m Y+\log k_{o}$

which is displayed in Figure 2 and a value of $\mathrm{m}=0.8$ was found. Winstein - Grunwald $\mathrm{Y}_{\mathrm{tBuCl}}$ values for acetonitrile-water mixtures: $\mathrm{Y}_{90 \% \mathrm{MeCN}}=-1.23 ; \mathrm{Y}_{80 \% \mathrm{MeCN}}=-0.14 .35$ Values for intermediate mixtures were determined from the plot of $\mathrm{Y}$ vs. $\mathrm{MeCN}$ percentage: $\mathrm{Y}_{87 \% \mathrm{MeCN}}=$ - 
$0.97 ; \mathrm{Y}_{83 \% \mathrm{MeCN}}=-0.53$.

Determination of activation parameters for reaction of norbornene with NBS. To 1,2 mmol of norbornene in a mixture of $30 \mathrm{~mL}$ acetonitrile and $10 \mathrm{~mL}$ water was added NBS (0.6 mmol) dissolved in $20 \mathrm{~mL}$ acetonitrile. All solutions were thermostatted at temperatures of 5, 10, 15 and $18{ }^{\circ} \mathrm{C}$, stirred and aliquots iodometrically titrated at various times. The linear correlation observed between $\log \mathrm{k}_{2}$ and reciprocal temperature is shown in Figure 1 and activation parameters were calculated from the formula:

$\ln \left(k_{2} / T\right)=\ln \left(k_{B} / h\right)+\Delta S^{*} / R-\Delta \mathrm{H}^{*} / R T$

\section{References and Notes}

1. Traylor, T. G. Acc. Chem. Res. 1969, 2, 152.

2. Mayr, H.; Patz, M. Angew. Chem. 1994, 106, 990.

3. Ruasse, M.-F. Adv. Phys. Org. Chem. 1993, 28, 207.

4. Patai, S., Ed.; The chemistry of the carbon-halogen bond, John Wiley \& Sons: London, 1973.

5. Patai, S.; Rappoport, Z. Eds., The chemistry of halides, pseudo-halides and azides, Supplement D, John Wiley \& Sons: Chichester, 1983.

6. Patai, S.; Rappoport, Z. Eds., The chemistry of halides, pseudo-halides and azides, Supplement D2, John Wiley \& Sons: Chichester, 1995.

7. Freeman, F. Chem. Rev. 1975, 75, 439.

8. Collin, G.; Jahnke, U.; Just, G.; Lorenz, G.; Pritzkow, W.; Rollig, M.; Winguth, L.; Dietrich, P.; Doering, C. E.; Hauthal, H. G.; Wiedenhoeft, A. J. Prakt. Chem. 1969, 311, 238.

9. Bailey, A. S.; White, J. E. J. Chem. Soc. (B) 1966, 819.

10. Isaacs, N. S. Physical organic chemistry; Addison Wesley Longman: Harlow, 1996.

11. Grunwald, E.; Winstein, S. J. Am. Chem. Soc. 1948, 70, 846.

12. Ruasse, M. F.; Motallebi, S.; Galland, B. J. Am. Chem. Soc. 1991, 113, 3440.

13. March, J. Advanced organic chemistry, John Wiley \& Sons: New York, $4^{\text {th }}$ Edn., 1992.

14. Price, D.; Iddon, B.; Wakefield, B. J. Eds., Bromine compounds, Chemistry and Applications, Elsevier: Amsterdam, 1988.

15. Meinwald, J.; Meinwald, Y. C.; Baker, T. N. J. Am. Chem. Soc. 1963, 85, 2513.

16. Bingham, K. D.; Meakins, G. D.; Whitman, G. H. J. Chem. Soc. Chem. Commun. 1966, 445.

17. Kwart, H.; Nyce, J. L. J. Am. Chem. Soc. 1964, 86, 2601.

18. Kwart, H.; Miller, R. K. J. Am. Chem. Soc. 1956, 78, 5678.

19. Arnold, D. R.; Snow, M. S. Can. J. Chem. 1988, 60, 3012.

20. Merritt, R. F., U. S. Patent 3,487,093, 1969; Chem. Abstr. 1970, 72, 78758j.

21. Poutsma, M. L. J. Am. Chem. Soc. 1965, 87, 4293.

22. Marshal, D. R.; Reynolds-Warnhoff, P.; Warnhoff, E. W.; Robinson, J. R. Can. J. Chem. 1971, 49, 885 . 
23. Werstiuk, N. H.; Wancas, I.; Warkentin, J.; Clark, F. R. S. Can. J. Chem. 1972, 50, 291.

24. Dalton, D. R.; Rodebaugh, R. K.; Jefford, C. W. J. Org. Chem. 1972, 37, 362.

25. Stavber, S.; Sotler, T.; Zupan, M. Tet. Lett. 1994, 35, 1105.

26. Stavber, S.; Zupan, M.; Poss, A. J.; Shia, G. A. Tet. Lett. 1995, 36, 6769.

27. Stavber, S.; Sotler-Pečan, T.; Papež, M.; Zupan, M. J. Chem. Soc., Chem. Commun. 1996, 2247.

28. Zupan, M.; Škulj, P.; Stavber, S. Chem. Lett. 1988, 641.

29. Stavber, S.; Sotler-Pečan, T.; Zupan, M. Tetrahedron 2000, 56, 1929.

30. Stavber, S.; Sotler-Pečan, T.; Zupan, M. J. Chem. Soc., Perkin Trans. 2 2000, 1141.

31. Carlson, R.G.; Behn, N. S.; Cowles, C. J. Org. Chem. 1971, 36, 3832.

32. Olah, G. A.; Nojima, M.; Kerekes, I. Synthesis 1973, 780.

33. Gregorčič, A.; Zupan, M. Coll. Czech. Chem. Comunn. 1977, 42, 3192.

34. Kleinpeter, E.; Haufe, G.; Borsdorf, R. J. Prakt. Chem. 1980, 322, 125.

35. Bentley, T. W.; Dau-Schmidt, J-P.; Llewellyn, G.; Mayr, H. J. Org. Chem. 1992, 57, 2387. 